\title{
Reduction in surgical site infection with suprafascial intrawound application of vancomycin powder in instrumented posterior spinal fusion: a retrospective case-control study
}

\author{
Shoichi Haimoto, MD, ${ }^{1,2}$ Ralph T. Schär, MD, ${ }^{1}$ Yusuke Nishimura, MD, PhD, ${ }^{2}$ \\ Masahito Hara, MD, PhD, ${ }^{3}$ Toshihiko Wakabayashi, MD, PhD, ${ }^{2}$ and \\ Howard J. Ginsberg, MD, PhD, FRCSC ${ }^{1}$
}

'Division of Neurosurgery, St. Michael's Hospital, University of Toronto, Toronto, Ontario, Canada; 2 Department of Neurosurgery, Nagoya University Graduate School of Medicine, Nagoya; and ${ }^{3}$ Department of Neurosurgery, Inazawa Municipal Hospital, Inazawa, Japan

\begin{abstract}
OBJECTIVE Recent studies have demonstrated the efficacy of subfascial intrawound application of vancomycin powder in spine surgery in reducing the rate of surgical site infections (SSIs). However, to date no study has evaluated the efficacy and safety of suprafascial application of vancomycin powder in spine surgery. The purpose of this study was to quantify the rate of SSIs after open instrumented posterior spinal fusion with and without application of suprafascial vancomycin powder and to evaluate the rate of vancomycin powder-related local adverse effects.
\end{abstract}

METHODS The authors conducted a single-center retrospective case-control study of adult patients undergoing open instrumented posterior fusion of the cervical, thoracic, or lumbar spine performed by a single surgeon from January 2010 through December 2016. In March 2013, routine application of $1 \mathrm{~g}$ of suprafascial vancomycin powder was started for all cases in addition to standard systemic antibiotic prophylaxis. Baseline demographics and operative data as well as the SSI rates were compared between the study groups. The incidence of vancomycin powder-related adverse effects was analyzed.

RESULTS A total of 515 patients (268 in the untreated group and 247 in the treated group) were included in the study. The mean age was significantly higher in the treated group than in the untreated group (58.4 vs 54.4 years, $p<0.01$ ). Operative variables were similar between the study groups. Patients receiving vancomycin powder had a significantly lower infection rate $(5.6 \%$ in the untreated group vs $0 \%$ in the treated group, $p<0.001)$. No vancomycin powder-related adverse effects were identified in the treated group.

CONCLUSIONS Routine application of suprafascial intrawound vancomycin powder in addition to systemic antibiotic prophylaxis is an easy-to-use, safe, and effective strategy for preventing SSIs after instrumented posterior spinal fusion. Suprafascial application of vancomycin powder could be a valuable alternative to previously reported subfascial distribution, minimizing the risk of local adverse drug reactions.

https://thejns.org/doi/abs/10.3171/2017.12.SPINE17997

KEYWORDS surgical site infection; vancomycin powder; suprafascial application; adverse drug reaction; spine surgery; posterior spinal fusion

$\mathrm{D}$ ESPITE the use of perioperative systemic antibiotic prophylaxis, surgical site infections (SSIs) remain a serious complication in spine surgery, particularly in instrumented spinal fusion. SSIs can have a profound negative impact on patient outcomes and burden the health care system by leading to revision surgery, lengthy use of systemic antibiotics, and prolonged hospitalization. . $^{11,18,25,26}$

In recent years the use of intrawound vancomycin powder in spine surgery has emerged as a promising method to address these concerns. Many, mainly retrospective stud-

ABBREVIATIONS ASA = American Society of Anesthesiologists; CSF = cerebrospinal fluid; DBM = demineralized bone matrix; IV = intravenous; SSI = surgical site infection.

SUBMITTED September 11, 2017. ACCEPTED December 12, 2017.

INCLUDE WHEN CITING Published online May 4, 2018; DOI: 10.3171/2017.12.SPINE17997. 
ies have reported the efficacy and safety of intrawound application of vancomycin powder. ${ }^{3,8,14,23,24,28-30}$ In a recent meta-analysis, the use of intrawound vancomycin powder was shown to significantly reduce the SSI rate from $4.1 \%$ to $1.3 \% .^{16}$ The standard dose of $1-2$ g reported in the literature, regardless of incision size, is empirical and not based on pharmacokinetic data. In prior studies guiding current use, vancomycin has been distributed either subfascially or simply "throughout the wound." $3,20,24,28-32$ A recent systematic review reported an overall drug-related complication rate for vancomycin powder of $0.3 \% .^{12}$ The most common adverse effect is culture-negative seroma formation, ${ }^{12,13}$ which may lead to severe neural compression requiring reoperation. This risk may be associated with subfascial vancomycin powder in direct proximity to exposed neural structures. ${ }^{33}$ The toxic impact of subfascial administration of vancomycin powder on bone healing with increased risk of nonunion is controversial but remains a serious concern. ${ }^{6,27}$

To date no studies have evaluated the efficacy and safety of solely suprafascial administration of vancomycin powder. With suprafascial distribution of vancomycin powder, there might be a potential reduction not only in SSIs but also in drug-related complications, which have been reported with subfascial administration.

The goal of this retrospective case-control study was to quantify and compare the SSI rates of patients undergoing instrumented posterior spinal fusion treated with and without suprafascial application of vancomycin powder in addition to standard perioperative systemic antibiotic prophylaxis. Secondly, we aimed to investigate the occurrence of vancomycin powder-related local and systemic adverse reactions as previously reported in the literature.

\section{Methods \\ Patient Selection}

The institutional review board of St. Michael's Hospital, University of Toronto, granted approval for this study. A retrospective review of all patients who underwent open instrumented posterior spinal fusion carried out by the senior author at the above-mentioned institution from January 2010 to December 2016 was performed. As a consequence of emerging literature with suggested benefits from the topical use of vancomycin powder in spine surgery, the senior author adopted this method in his practice with the distinct modification of suprafascial distribution. Thus, as of March 2013 vancomycin powder was administered routinely in all patients undergoing open instrumented posterior spinal fusion. Inclusion criteria for the study were patient age greater than 18 years of age and having undergone open posterior spinal fusion using screw and rod instrumentation at any level between the craniocervical and lumbosacral junction. Patients treated with minimally invasive surgery with percutaneous instrumentation, patients with a history of previous spine surgery at the index level, and patients with a postoperative follow-up period of less than 6 months were excluded from final analyses. Age; sex; spinal pathology categorized as degenerative, traumatic, infectious, or neoplastic; and risk factors for SSI, such as diabetes, obesity (defined as body mass index
TABLE 1. Comparison of baseline characteristics between the 2 groups

\begin{tabular}{lccr}
\hline \multicolumn{1}{c}{ Characteristic } & $\begin{array}{c}\text { Untreated } \\
\text { Group }(\mathrm{n}=268)\end{array}$ & $\begin{array}{c}\text { Treated Group } \\
(\mathrm{n}=247)\end{array}$ & $\begin{array}{c}\mathrm{p} \\
\text { Value }\end{array}$ \\
\hline Age in yrs, mean & $54.5 \pm 15.7$ & $58.4 \pm 15.1$ & $<0.01$ \\
\hline Sex, $\mathrm{n}(\%)$ & & & 0.65 \\
\hline Male & $168(62.7)$ & $150(60.1)$ & \\
\hline Female & $100(37.3)$ & $97(39.3)$ & \\
\hline Spinal pathology, $\mathrm{n}(\%)$ & & & 0.15 \\
\hline Degenerative & $123(45.9)$ & $131(53.0)$ & \\
\hline Traumatic & $101(37.7)$ & $89(36.0)$ & \\
\hline Infectious & $11(4.1)$ & $10(4.0)$ & \\
\hline Neoplastic & $33(12.3)$ & $17(6.8)$ & \\
\hline Location of surgery, $\mathrm{n}(\%)$ & & & \\
\hline Cervical & $86(32.1)$ & $50(20.2)$ & \\
\hline Cervicothoracic & $28(10.4)$ & $34(13.8)$ & \\
\hline Thoracic & $42(15.7)$ & $32(13.0)$ & \\
\hline Thoracolumbar & $31(11.6)$ & $37(15.0)$ & \\
\hline Lumbar & $81(30.2)$ & $94(38.1)$ & \\
\hline Diabetes, $\mathrm{n}(\%)$ & $37(13.8)$ & $45(18.2)$ & 0.19 \\
\hline Obesity, ${ }^{*} \mathrm{n}(\%)$ & $68(25.4)$ & $61(24.7)$ & 0.92 \\
\hline Tobacco use, $\mathrm{n}(\%)$ & $62(23.1)$ & $51(20.6)$ & 0.52 \\
\hline RA, $\mathrm{n}(\%)$ & $7(2.6)$ & $9(3.6)$ & 0.61 \\
\hline RA $\%$ rheumato & & & \\
\hline
\end{tabular}

$\mathrm{RA}=$ rheumatoid arthritis.

* Body mass index $>30 \mathrm{~kg} / \mathrm{m}^{2}$.

$>30 \mathrm{~kg} / \mathrm{m}^{2}$ ), tobacco use, and rheumatoid arthritis, were documented for each patient. Operative data of all cases, including the American Society of Anesthesiologists (ASA) Physical Status classification, operative time, estimated blood loss, number of instrumented levels, presence of interbody fusion, and surgical complications, were also extracted from the operative records (Tables 1 and 2). The untreated group consisted of patients who underwent surgery without application of vancomycin powder (January 2010 through February 2013); the treated group consisted of patients receiving vancomycin powder (March 2013 through December 2016). In the treated group, medical records and our surgical database were carefully reviewed to search for any evidence of postoperative complications, including renal failure, hearing loss, or seroma formation, as adverse events associated with intrawound vancomycin powder application.

\section{Perioperative Management}

Standard perioperative medical and anesthesiological patient care as well as the surgical technique used did not differ between patient groups. Preoperatively, 1 or 2 $\mathrm{g}$ of intravenous (IV) cefazolin was routinely given to all patients, with the dosage depending on the patient's body weight $(<80 \mathrm{~kg}$ or $\geq 80 \mathrm{~kg}), 30$ minutes before skin incision. For longer cases, antibiotic prophylaxis was repeated every 3 hours intraoperatively. Patients with a documented allergy to penicillin received $600 \mathrm{mg}$ of IV clindamycin instead. All operations were performed by the senior author with assistance of a clinical fellow and/or neurosur- 
TABLE 2. Comparison of operative data between the 2 groups

\begin{tabular}{lccc}
\hline \multicolumn{1}{c}{ Characteristic } & $\begin{array}{c}\text { Control } \\
\text { Group } \\
(\mathrm{n}=268)\end{array}$ & $\begin{array}{c}\text { Treatment } \\
\text { Group } \\
(\mathrm{n}=247)\end{array}$ & $\begin{array}{c}\mathrm{p} \\
\text { Value }\end{array}$ \\
\hline ASA PS classification, $\mathrm{n}(\%)$ & & & 0.83 \\
\hline 1 & $7(2.6)$ & $5(2.0)$ & \\
\hline 2 & $45(16.8)$ & $45(18.2)$ & \\
\hline 3 & $115(42.9)$ & $115(46.6)$ & \\
\hline 4 & $100(37.3)$ & $81(32.8)$ & \\
\hline 5 & $1(0.4)$ & $1(0.4)$ & \\
\hline 6 & $0(0)$ & $0(0)$ & \\
\hline Operative time in minutes, mean & $184 \pm 72$ & $182 \pm 58$ & 0.76 \\
\hline Blood loss in ml, mean & $532 \pm 548$ & $462 \pm 454$ & 0.12 \\
\hline No. of instrumented levels, mean & $4.0 \pm 1.8$ & $4.1 \pm 1.7$ & 0.49 \\
\hline Interbody fusion, $n(\%)$ & $61(22.8)$ & $70(28.3)$ & 0.16 \\
\hline CSF leakage, $n$ (\%) & $21(7.8)$ & $22(8.9)$ & 0.75 \\
\hline SSI, $n$ (\%) & $15(5.6)$ & $0(0)$ & $<0.001$ \\
\hline
\end{tabular}

ASA PS = American Society of Anesthesiologists Physical Status.

gery resident. A midline skin incision and standard open approach were performed in all cases. All pedicle screws and-if deemed necessary-lateral mass and C-2 pars screws in the cervical spine were placed using a navigation system with intraoperative surface-matched registration based on 3D reconstruction of a preoperative CT. A subfascial closed suction drain was placed at the end of surgery in each case except for cases with incidental durotomy and cerebrospinal fluid (CSF) leakage. Wound closure was performed in a layered fashion. In the treatment group, $1 \mathrm{~g}$ of vancomycin powder was applied over the tightly closed fascia (Fig. 1). The drain was removed on postoperative day 1 or 2 , and skin staples were removed 10 to 14 days postoperatively.

\section{Outcomes}

The primary outcome evaluated in this study was the incidence of SSI requiring surgical debridement with or without hardware removal. Minor wound issues such as stitch abscesses were not considered a relevant SSI. As a secondary outcome measure, we analyzed the occurrence of vancomycin powder-related local and systemic complications in the treatment group.

\section{Statistical Analysis}

Baseline characteristics and operative data were compared between the 2 groups using Fisher's exact test for categorical variables and the Student t-test for continuous variables. Univariate analysis using Fisher's exact test was performed to evaluate the difference in infection rate. Results are represented as mean \pm standard deviation. A p value less than 0.05 was considered statistically significant. All statistical analyses were performed using the SPSS 22.0 statistics package (IBM Corp.).

\section{Results}

\section{Patient Population}

A total of 515 patients were included in the study. There

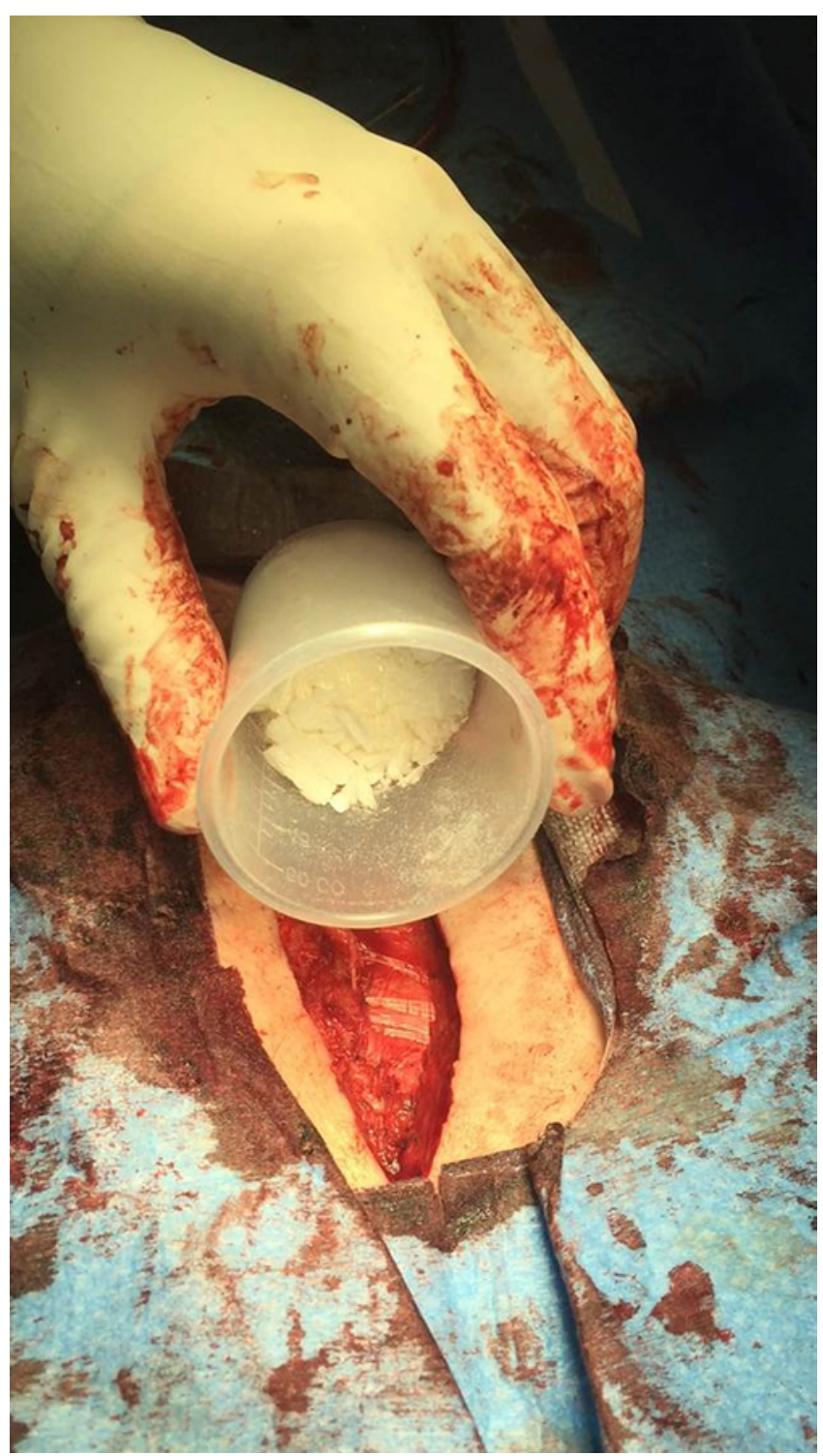

FIG. 1. Intraoperative image demonstrating closure of the muscle fascia before intrawound vancomycin powder application. Figure is available in color online only.

were $268(52.0 \%)$ patients in the control group and 247 $(48.0 \%)$ patients in the treatment group. Comparison of baseline characteristics between the 2 groups is summarized in Table 1. There were no significant differences in any of the demographic characteristics except for age. The mean age was significantly higher in the treatment group $(58.4 \pm 15.1$ years) than in the control group $(54.5 \pm 15.7$ years).

\section{Perioperative Outcomes}

Operative variables, including ASA Physical Status classification, operative time, estimated blood loss, number of instrumented levels, and presence of interbody fusion, were all similar between the 2 groups. Unintentional durotomy with CSF leakage was observed in 21 cases (7.8\%) in the control group and 22 cases (8.9\%) in the treatment group. The incidence of this surgical complication did not 
differ significantly between the 2 groups. There were a total of 15 SSIs (5.6\%) in the control group compared with none $(0 \%)$ in the treatment group. This reduction in SSIs was statistically significant $(\mathrm{p}<0.001)$. Results are detailed in Table 2. In the treatment of SSIs, 6 of 15 patients required either hardware replacement or removal, and the remaining 9 patients improved with surgical debridement. No adverse events, such as postoperative culture-negative seroma formation, nephropathy, or ototoxicity, related to topical use of vancomycin powder in the treatment group were observed.

\section{Discussion}

This is the first study evaluating the efficacy and safety of routine suprafascial application of vancomycin powder for prophylaxis of SSI in spine surgery. In our series, patients receiving suprafascial vancomycin powder had a significant reduction in the incidence of SSI (from 5.6\% to $0 \%$ ) and no drug-related complications. Furthermore, the mean age was significantly higher in the treated group compared with the untreated group. Given the fact that advanced age is a well-known risk factor for SSI, 4,10,17,21 our results underline the efficacy of suprafascial application of vancomycin powder in reducing SSI.

\section{Dose and Distribution of Vancomycin Powder}

In the wake of multiple clinical studies on intrawound vancomycin powder for reduction of SSI, this strategy has become a routine practice for many spine surgeons. However, there is still a lack of high-quality evidence for the use of intrawound vancomycin powder in spine surgery, with nearly all data coming from retrospective case series. A systematic review concluded that surgeons should be cautious in widely adopting this intervention and should be vigilant in monitoring for adverse effects. ${ }^{9}$ In the present study, $1 \mathrm{~g}$ of vancomycin powder, regardless of incision size, was applied to the wound strictly after closure of the muscle fascia, thus avoiding direct exposure of neural structures, vertebrae, bone graft, and instrumentation to vancomycin. There is still a large heterogeneity in the literature, with the dose and distribution of vancomycin powder varying for each protocol. Some authors have reported applying $1 \mathrm{~g}$ of vancomycin powder subfascially alongside the bone graft and instrumentation, ${ }^{3}$ whereas others simply recommend distributing $2 \mathrm{~g}$ of vancomycin powder basically anywhere beneath the fascia. ${ }^{31}$ Other studies emphasize placing vancomycin powder both suband suprafascially directly on the muscle, the fascia, and subcutaneous tissue..$^{20,24,28,32}$ To the best of our knowledge, there are no previous studies designed to determine the optimum dose and distribution of intrawound vancomycin powder application in spine surgery.

\section{Vancomycin-Related Adverse Drug Reactions}

The major advantage of local antibiotic treatment is the prospect of low systemic toxicity. In fact, the literature seems to suggest a much higher risk for local adverse effects as compared with systemic toxicity when using intrawound vancomycin powder in spine surgery. A recent systematic review reported a very low incidence of drugrelated complications from the use of intrawound vanco- mycin powder, with merely 23 adverse events identified out of 6701 patients $(0.3 \%)$ in 16 studies. Only 4 patients suffered systemic toxicity (2 ototoxicity, 1 nephropathy, and 1 systemic absorption resulting in supratherapeutic exposure), with the remaining 19 patients experiencing culture-negative seroma formation..$^{12}$ The latter following subfascial administration of vancomycin powder may lead to urgent surgical intervention due to severe compression of neural structures. This has been previously reported and authors have hypothesized a focal acute allergic reaction to the powdered drug as a likely cause. ${ }^{33}$

The potential toxic effect of intrawound vancomycin powder on bone healing is of major interest in spine surgery and has been extensively investigated. Edin et al. hypothesized that a high local concentration $(10,000 \mu \mathrm{g} /$ $\mathrm{ml}$ ) of antimicrobials may induce osteoblast cell death. Analysis of wound drainage fluids after intrawound vancomycin powder application demonstrated local concentration levels of merely $1500 \mu \mathrm{g} / \mathrm{ml} ;{ }^{30}$ however, it is argued that peak concentrations at the application site might be significantly higher. Eder et al. suggested that high dosages of intrawound vancomycin powder reduce migration, proliferation, and mineralization of osteoblasts and therefore might increase the risk of nonunion. ${ }^{6} \mathrm{An}$ in vivo study demonstrated that the addition of vancomycin to demineralized bone matrix (DBM) reduced the fusion capability of the DBM graft in posterolateral fusion. ${ }^{27}$ Currently, little is known about the impact of intrawound vancomycin powder on the true risk for pseudarthrosis. Existing retrospective studies fail to report compelling data on the subject and show no significant differences in pseudoarthrosis rates in patients treated with or without intrawound vancomycin powder due to small patient numbers, shortterm follow-up, or insufficient radiological study. ${ }^{28,30}$

Apart from bone healing, it has been thought that topical vancomycin powder application may also interfere with dural repair. Goldschmidt et al. described that high concentrations of vancomycin (up to $4000 \mu \mathrm{g} / \mathrm{ml}$ ) induce dural cell death and therefore might have a deleterious effect on dural healing in cases of intentional or unintentional durotomies. ${ }^{15}$

Considering all mentioned local adverse drug reactions, shifting peak drug concentrations away from these sensitive and critical subfascial structures seems to be a key factor. Adverse effects on healing of bone and neural elements, as well as postoperative subfascial seroma formation, might be better averted with strict suprafascial application of vancomycin powder while reducing the rate of SSIs nonetheless. Also, as another advantage of this method, suprafascial vancomycin powder is less likely to get washed out with subfascial drains than in cases where the powder is placed in that same compartment, thus compromising the intended antimicrobial effect.

\section{Impact of Vancomycin Powder on Wound Healing}

For most SSIs in spine surgery, the source of pathogens is the patient's endogenous skin flora. ${ }^{1,2,19}$ Therefore, suprafascial distribution seems to be an appropriate first line of defense leading to high vancomycin concentration levels close to the skin, thereby reducing the subcutaneous bacterial load, and ultimately decreasing the risk of SSI. 
Once skin is incised, the exposed tissues remain at risk for contamination with endogenous flora until healing of the wound is completed. Wound healing occurs through 4 phases, namely hemostasis, inflammation, proliferation, and remodeling. ${ }^{22}$ The role of inflammation is to prepare the wound bed for healing by removing necrotic tissue and bacterial contaminant, and it usually occurs within the first 3 days after wounding. ${ }^{5}$ Intrawound vancomycin powder is thought to accelerate the inflammation process by reducing bacterial load and therefore may potentially facilitate wound healing.

\section{Study Limitations}

There are limitations to this study inherent to its retrospective design. There is a hypothetical possibility of underreporting of relevant postoperative infections and drug-related reactions. However, due to the fact that this was a single-center, single-surgeon study, this is highly unlikely. Also, relevant SSIs or large seroma formations would have required surgical revision and would have therefore been easily registered.

\section{Conclusions}

Routine application of suprafascial intrawound vancomycin powder in addition to systemic antibiotic prophylaxis is an easy-to-use, safe, and effective strategy for preventing SSIs after instrumented posterior spinal fusion. Suprafascial application of vancomycin powder could be a valuable alternative to previously reported subfascial distribution by minimizing the risk of local adverse drug reactions.

\section{References}

1. Altemeier WA, Culbertson WR, Hummel RP: Surgical considerations of endogenous infections-sources, types, and methods of control. Surg Clin North Am 48:227-240, 1968

2. Anderson PA, Savage JW, Vaccaro AR, Radcliff K, Arnold PM, Lawrence BD, et al: Prevention of surgical site infection in spine surgery. Neurosurgery 80 (3S):S114-S123, 2017

3. Caroom C, Tullar JM, Benton EG Jr, Jones JR, Chaput CD: Intrawound vancomycin powder reduces surgical site infections in posterior cervical fusion. Spine (Phila Pa 1976) 38:1183-1187, 2013

4. Chaichana KL, Bydon M, Santiago-Dieppa DR, Hwang L, McLoughlin G, Sciubba DM, et al: Risk of infection following posterior instrumented lumbar fusion for degenerative spine disease in 817 consecutive cases. J Neurosurg Spine 20:45-52, 2014

5. Chen X, Liu Y, Zhang X: Topical insulin application improves healing by regulating the wound inflammatory response. Wound Repair Regen 20:425-434, 2012

6. Eder C, Schenk S, Trifinopoulos J, Külekci B, Kienzl M, Schildböck S, et al: Does intrawound application of vancomycin influence bone healing in spinal surgery? Eur Spine J 25:1021-1028, 2016

7. Edin ML, Miclau T, Lester GE, Lindsey RW, Dahners LE: Effect of cefazolin and vancomycin on osteoblasts in vitro. Clin Orthop Relat Res (333):245-251, 1996

8. Emohare O, Ledonio CG, Hill BW, Davis RA, Polly DW Jr, Kang MM: Cost savings analysis of intrawound vancomycin powder in posterior spinal surgery. Spine J 14:2710-2715, 2014

9. Evaniew N, Khan M, Drew B, Peterson D, Bhandari M,
Ghert M: Intrawound vancomycin to prevent infections after spine surgery: a systematic review and meta-analysis. Eur Spine J 24:533-542, 2015

10. Fang A, Hu SS, Endres N, Bradford DS: Risk factors for infection after spinal surgery. Spine (Phila Pa 1976) 30:14601465,2005

11. Gerometta A, Rodriguez Olaverri JC, Bitan F: Infections in spinal instrumentation. Int Orthop 36:457-464, 2012

12. Ghobrial GM, Cadotte DW, Williams K Jr, Fehlings MG, Harrop JS: Complications from the use of intrawound vancomycin in lumbar spinal surgery: a systematic review. Neurosurg Focus 39(4):E11, 2015

13. Ghobrial GM, Thakkar V, Andrews E, Lang M, Chitale A, Oppenlander ME, et al: Intraoperative vancomycin use in spinal surgery: single institution experience and microbial trends. Spine (Phila Pa 1976) 39:550-555, 2014

14. Godil SS, Parker SL, O’Neill KR, Devin CJ, McGirt MJ: Comparative effectiveness and cost-benefit analysis of local application of vancomycin powder in posterior spinal fusion for spine trauma: clinical article. J Neurosurg Spine 19:331-335, 2013

15. Goldschmidt E, Rasmussen J, Chabot JD, Gandhoke G, Luzzi E, Merlotti L, et al: The effect of vancomycin powder on human dural fibroblast culture and its implications for dural repair during spine surgery. J Neurosurg Spine 25:665-670, 2016

16. Khan NR, Thompson CJ, DeCuypere M, Angotti JM, Kalobwe E, Muhlbauer MS, et al: A meta-analysis of spinal surgical site infection and vancomycin powder. J Neurosurg Spine 21:974-983, 2014

17. Klemencsics I, Lazary A, Szoverfi Z, Bozsodi A, Eltes P, Varga PP: Risk factors for surgical site infection in elective routine degenerative lumbar surgeries. Spine J 16:13771383,2016

18. Lazennec JY, Fourniols E, Lenoir T, Aubry A, Pissonnier ML, Issartel B, et al: Infections in the operated spine: update on risk management and therapeutic strategies. Orthop Traumatol Surg Res 97 (6 Suppl):S107-S116, 2011

19. Mangram AJ, Horan TC, Pearson ML, Silver LC, Jarvis WR: Guideline for prevention of surgical site infection, 1999. Am J Infect Control 27:96-134, 1999

20. Martin JR, Adogwa O, Brown CR, Kuchibhatla M, Bagley CA, Lad SP, et al: Experience with intrawound vancomycin powder for posterior cervical fusion surgery. J Neurosurg Spine 22:26-33, 2015

21. Massie JB, Heller JG, Abitbol JJ, McPherson D, Garfin SR: Postoperative posterior spinal wound infections. Clin Orthop Relat Res (284):99-108, 1992

22. Menke MN, Menke NB, Boardman CH, Diegelmann RF: Biologic therapeutics and molecular profiling to optimize wound healing. Gynecol Oncol 111 (2 Suppl):S87-S91, 2008

23. Molinari RW, Khera OA, Molinari WJ III: Prophylactic intraoperative powdered vancomycin and postoperative deep spinal wound infection: 1,512 consecutive surgical cases over a 6-year period. Eur Spine J 21 (Suppl 4):S476-S482, 2012

24. O'Neill KR, Smith JG, Abtahi AM, Archer KR, Spengler $\mathrm{DM}, \mathrm{McGirt} \mathrm{MJ}$, et al: Reduced surgical site infections in patients undergoing posterior spinal stabilization of traumatic injuries using vancomycin powder. Spine J 11:641-646, 2011

25. Sasso RC, Garrido BJ: Postoperative spinal wound infections. J Am Acad Orthop Surg 16:330-337, 2008

26. Savage JW, Anderson PA: An update on modifiable factors to reduce the risk of surgical site infections. Spine J 13:10171029,2013

27. Shiels SM, Raut VP, Patterson PB, Barnes BR, Wenke JC: Antibiotic-loaded bone graft for reduction of surgical site infection in spinal fusion. Spine J 17:1917-1925, 2017 
28. Strom RG, Pacione D, Kalhorn SP, Frempong-Boadu AK: Decreased risk of wound infection after posterior cervical fusion with routine local application of vancomycin powder. Spine (Phila Pa 1976) 38:991-994, 2013

29. Strom RG, Pacione D, Kalhorn SP, Frempong-Boadu AK: Lumbar laminectomy and fusion with routine local application of vancomycin powder: decreased infection rate in instrumented and non-instrumented cases. Clin Neurol Neurosurg 115:1766-1769, 2013

30. Sweet FA, Roh M, Sliva C: Intrawound application of vancomycin for prophylaxis in instrumented thoracolumbar fusions: efficacy, drug levels, and patient outcomes. Spine (Phila Pa 1976) 36:2084-2088, 2011

31. Theologis AA, Demirkiran G, Callahan M, Pekmezci M, Ames C, Deviren V: Local intrawound vancomycin powder decreases the risk of surgical site infections in complex adult deformity reconstruction: a cost analysis. Spine (Phila Pa 1976) 39:1875-1880, 2014

32. Tubaki VR, Rajasekaran S, Shetty AP: Effects of using intravenous antibiotic only versus local intrawound vancomycin antibiotic powder application in addition to intravenous antibiotics on postoperative infection in spine surgery in 907 patients. Spine (Phila Pa 1976) 38:2149-2155, 2013

33. Youssef JA, Orndorff DG, Scott MA, Ebner RE, Knewitz
AP: Sterile seroma resulting from multilevel XLIF procedure as possible adverse effect of prophylactic vancomycin powder: a case report. Evid Based Spine Care J 5:127-133, 2014

\section{Disclosures}

The authors report no conflict of interest concerning the materials or methods used in this study or the findings specified in this paper.

\section{Author Contributions}

Conception and design: Ginsberg, Haimoto, Schär. Acquisition of data: Haimoto. Analysis and interpretation of data: Haimoto. Drafting the article: Haimoto, Schär. Critically revising the article: all authors. Reviewed submitted version of manuscript: all authors. Approved the final version of the manuscript on behalf of all authors: Ginsberg. Administrative/technical/material support: Ginsberg. Study supervision: Ginsberg.

\section{Correspondence}

Howard J. Ginsberg: St. Michael's Hospital, University of Toronto, ON, Canada. ginsbergh@smh.ca. 